\title{
Postencephalitic Parkinsonism
}

National Cancer Institute

\section{Source}

National Cancer Institute. Postencephalitic Parkinsonism. NCI Thesaurus. Code C34898.

Parkinsonism resulting from encephalitis. 